\title{
A DOCUMENTAÇÃO MUSEOLÓGICA E OS NOVOS PARADIGMAS DA ARTE CONTEMPORÂNEA
}

\author{
Mariana Estellita Lins Silva ${ }^{1 *}$
}

\section{RESUMO:}

Buscaremos discutir a relação que a arte contemporânea - especificamente obras efêmeras, perecíveis e relacionais, que problematizam a função do objeto no processo artístico - estabelece com a teoria e a prática da documentação museológica. Inicialmente apresentaremos os fundamentos teóricos da documentação e em seguida passaremos para sua aplicação no tratamento de obras de arte tradicionais. Por último, procuraremos identificar os pontos problemáticos trazidos com as novas linguagens da arte contemporânea.

\section{PALAVRAS-CHAVES:}

Museologia. Documentação. Documento. Arte contemporânea. Imaterialidade.

\begin{abstract}
:
We seek to discuss the relationship that contemporary art specifically ephemeral, perishable and relational works that question the role of the object in the artistic process - down to the theory and practice of museum documentation. Initially we present the theoretical foundations of museum documentation and then move on to its application in the treatment of traditional works of art. Finally, we will seek to identify problem areas brought with the new languages of contemporary art.
\end{abstract}

\section{KEY-WORDS:}

Museology. Documentation. Document. Contemporary art. Immateriality.

I * Museóloga pela Universidade Federal do Estado do Rio de Janeiro - Unirio, mestre em História e Crítica de Arte pela Escola de Belas Artes da Universidade Federal do Rio de Janeiro - UFRJ. 
A documentação museológica se estrutura a partir do conceito de documento. Ao contrário de Jesse Shera e Louis Shores que restringem esta noção aos registros gráficos e textuais produzidos intencionalmente com tal finalidade, utilizaremos a definição de Paul Otlet (Smit, 2008), que considera que um objeto também pode ser um documento, na medida em que é deslocado de sua função ordinária e é colocado em uma coleção museológica por ser considerado um testemunho de um tempo e lugar. Desta forma, mesmo que não tenha sido produzido com este propósito, um objeto pode desempenhar a função de documento.

Briet trabalha o conceito de documento vinculado à existência de uma evidência material. A autora sintetiza três aspectos estruturantes para a caracterização de um documento:

I) A materialidade: a noção de documento se aplica apenas a sinais físicos;

2) A intencionalidade: pretende- se que o objeto seja tratado como evidencia;

3) O processamento: os objetos devem ter sido processados, ou seja, devem ter sido tornados documentos (BRIET apud LOUREIRO, 2008, p. I05).

Diante desta perspectiva, podemos observar a que a materialidade é condição fundamental para a existência de um documento. É a partir do suporte material que são desdobrados os potenciais simbólicos e informacionais de um objeto.

Partindo da perspectiva do sujeito, Le Goff (2003a; 2003b) afirma que um objeto não se constitui a priori como um documento, mas deve ser compreendido como tal na medida em que é lançado sobre ele este olhar. De outro modo: o que faz um objeto se tornar documento é a atribuição de valor simbólico que o destaca do universo dos objetos comuns. Nesta operação, há um investimento de memória, onde lhe é atribuído uma capacidade de recuperação e de comunicação de informações de um tempo a outro.

Compreendemos também, com Pomian (1984) que quando um objeto é inserido em uma coleção museológica, é destituído de sua função e seu uso originários para adquirir a função documental e comunicacional, e que seu valor de troca é ampliado, embora tenha se descontinuado seu valor de uso, precisamente pelo reconhecimento de sua relevância simbólica.

No entanto, percebemos as obras de arte como uma categoria especial de documento. Diferentes dos objetos históricos, que são criados inicialmente para uma função utilitária e quando investidos de valor simbólico são afastados desta função original para se tornarem documento, podemos considerar que as obras de arte nascem como objetos estéticos. $O$ objeto de arte é criado a fim de possibilitar a experiência estética, e essa função é mantida no ambiente do museu. Uma obra de arte no contexto museológico não passa a ser somente um objeto histórico ou um documento, mas continua sendo apresentada e fruída pelo público como objeto estético. Desta forma, o objeto artístico musealizado sobrepõe duas dimensões: a estética e a documental.

Uma pintura, por exemplo, é um objeto estético, contemplativo, que ao ser incorporado à coleção de um museu passa a ser legitimada não só como testemunho do tempo no qual foi produzida, como por ter sido resultado de um momento único de criação do artista, e por agregar em sua materialidade a unicidade do gestual presente em sua fatura. Ela se torna, portanto um documento, um suporte material, investido de valor simbólico que faz desta pintura um potencial comunicador.

Neste sentido, continuaremos com o exemplo da pintura para, agora, analisarrmos a prática da documentação museológica aplicada ao objeto de arte tradicional.Ao ser incorporada à coleção do museu, a pintura será identificada segundo suas características materiais, simbólicas e contextuais.A partir desta obra de arte, são extraídas informações em dois níveis: as informações intrínsecas e as informações extrínsecas. 
As informações intrínsecas de uma pintura dizem respeito às suas dimensões, à técnica e aos materiais aplicados em sua fatura etc. Já as informações extrínsecas são as de natureza contextual, que não podem ser apreendidas a partir da fisicalidade do objeto, e, portanto, são oriundas de pesquisas em outros documentos, que não a obra em si. Incluem-se, aí, as informações sobre o estilo artístico, as transformações históricas em voga no período em que foi elaborada, dados importantes sobre o autor etc.

Esta prática documental estruturada a partir destas duas categorias de informação é sustentada por Ferrez (1994, p. 2), onde:

Os objetos produzidos pelo homem são portadores de informações intrínsecas e extrínsecas que, para uma abordagem museológica, precisam ser identificadas.

As informações intrínsecas são deduzidas do próprio objeto, através da análise das suas qualidades físicas. As informações extrínsecas denominadas por MENSCH (I) de informações documental e contextual, são aquelas obtidas de outras fontes que não o objeto [...]

Portanto, as informações intrínsecas e extrínsecas identificam a obra de arte em seus aspectos singulares. Além disso, obras de arte necessitam ser localizadas dentro do contexto de uma coleção museológica. Por isso, o trabalho de documentação ocupa-se também da classificação das obras em categorias hierárquicas. Sendo assim, as obras de arte tradicionais são divididas em "pinturas", “esculturas”, "gravuras" etc. Dentro da categoria "pintura", as obras podem ser subdivididas pelo suporte (tela, papel, tecido etc) e pelo material (óleo, guache, aquarela, têmpera etc). Desta forma, o sistema de documentação deve ser capaz de nos remeter à obra que procuramos: uma pintura a óleo sobre tela, por exemplo.

Nesta estrutura hierárquica, as palavras utilizadas na busca são fundamentais para a recuperação da informação, pois é através dos termos específicos que identificamos os conjuntos e localizamos o objeto procurado. Podemos afirmar então que o controle do vocabulário é essencial para a sistematização e busca de informações neste sistema.

No entanto, no caso de uma obra de arte contemporânea, como inserir neste sistema de documentação uma obra que se caracteriza por ser uma proposição imaterial, efêmera e/ou relacional? Tomemos como exemplo a obra Sem Título, 1992, Rirkrit Tiravanija pertence à coleção do Museu de Arte Moderna de Nova York (MoMA), que consiste em uma proposição onde o artista cozinha e serve frango e arroz ao curry no espaço expositivo. Nesta obra, o ato de cozinhar, o preenchimento do espaço pelo aroma peculiar da receita de origem tailandesa e o compartilhamento do alimento são formas do artista trazer ao público seus referenciais pessoais e memórias afetivas de sua infância.A obra provoca um deslocamento da relação espectador $x$ artista, produz uma coletividade instantânea e problematiza os padrões de comportamento a que estamos submetidos cotidianamente.

Retomando nossa pergunta, indagaríamos: quais seriam, nesta obra, as informações intrínsecas? Como preencheríamos os campos "dimensões"2 e "técnica/materiais"? Neste caso como não há um objeto material identificável como obra, os campos “dimensões”, “técnica/materiais” sequer poderiam ser distinguíveis e mensurados.

Através deste exemplo, podemos sintetizar algumas questões para a documentação aplicada à arte contemporânea. A obra de Tiravanija, ao contrário da

2 Para o MoMA, a obra parece ser tratada como uma escultura, ou como uma instalação. As especificações são Medium: Refrigerator, table, chairs, wood, drywall, food and other materials / Dimensions: Dimensions variable ou [Técnica/Materiais: geladeira, mesa, cadeiras, madeira, drywall, comida e outros materiais / Dimensões: Dimensões variadas.]. Disponível em: <http://www.moma.org/collection/browse_results.php?crite ria=O\%3AAD\%3AE\%3A7479\&page_number=2\&template_id=| \&sort_order=|>.Acesso em: $\mid 5$ ago. 2012. 
pintura sobre tela do exemplo anterior, não se enquadra nas características reconhecidas de um documento - materialidade, intencionalidade e processamento. Embora seja uma obra de arte em uma coleção museológica, e, portanto se enquadra nas categorias de intencionalidade e processamento, esta obra de arte prescinde da materialidade e neste sentido, não poderia ser considerada um documento.

As informações intrínsecas, ou observáveis a partir da materialidade da obra, neste caso viriam dos pratos e talheres utilizados na ação, pois eles são a materialidade possível para esta ação. No entanto esta materialidade não constitui e não comunica nenhum valor sobre o trabalho artístico. Nesta proposição incorporal, onde os elementos materiais presentes (louças e panelas sujas), não coincidem com a obra, não caberia manter a dicotomia entre informações intrínsecas e extrínsecas.Acabaríamos concluindo, que as informações extrínsecas adquirem uma conotação muito mais ampla do que a contextualização da obra. Relatos do público, entrevistas com o artista, e outros elementos que poderiam ser considerados contextuais em uma obra tradicional, seriam os responsáveis por permitir a compreensão da obra de arte, sua possível remontagem, ou, de maneira mais abrangente, seriam os elementos determinantes para a sua preservação. De outro modo: Se para um objeto material ou em uma obra de arte tradicional as informações extrínsecas permitem a ampliação da condição informacional do objeto como documento, no caso das obras contemporâneas imateriais ou relacionais essas informações e suas respectivas estruturações dentro de um sistema de documentação, são imprescindíveis para a existência da obra. A preservação dessa tipologia de acervo depende fundamentalmente dessa estrutura documental.

Outro aspecto se refere ao tráfego funcional de informações que permeia as instâncias e os departamentos do museu. Mais do que uma ferramenta para a execução do projeto institucional, a base de dados é fundamental para a manutenção das obras de suporte complexo. As linguagens efêmeras, imateriais ou relacionais, por prescindir da fisicalidade, dependem de mecanismos estratégicos de materialidade temporária. Essa condição de existência - que também se aplica às obras materiais, se utilizarem suportes não-convencionais - faz com que elas precisem ser desmembradas, seja porque seu suporte material exige controles climáticos diferenciados, ou porque a informação documental da obra (arquivos, fotos, vídeos, documentos, projetos de montagem, entrevistas com os artistas, etc.) precisa ser alocada nos respectivos setores do museu. No modelo institucional que conhecemos hoje, a fotografia precisa ser encaminhada ao setor iconográfico, o projeto ao arquivo, etc. Nesse ponto, é fundamental que haja eficiência na recuperação da informação e na reunião destes elementos que foram estrategicamente separados entre os respectivos setores. Eles precisam ser reagrupados sem nenhuma perda informacional. Do contrário, o ruído na informação ou a impossibilidade de recuperação desse trajeto feito pelas partes componentes da obra pelos setores da instituição, inviabiliza a recuperação da informação e provoca a destruição da obra, como no caso descrito por Freire (1999, p. 45-46):

Joseph Kosuth (EUA, 1945), um dos mais importantes artistas conceituais norte-americanos, apresentou no MoMA de Nova York o trabalho 'One and Three Chairs' (1965), onde justapôs a cadeira real às suas representações (definição de cadeira do dicionário e fotografia de cadeira).Apesar de ter sido adquirida pelo MoMA, essa obra foi destruída ao ser incorporada à coleção do museu, uma vez que a cadeira foi encaminhada ao Departamento de Design, a foto, ao Departamento de Fotografia, e a fotocópia da definição de cadeira, à biblioteca.

Por fim, é preciso destacar ainda, a problemática do vocabulário controlado e a hierarquia de categorias, elementos estruturais da documentação das obras 
tradicionais. $\mathrm{Na}$ arte contemporânea, essas divisões são expandidas, questionadas e dilatadas pelos próprios artistas. Novas categorias de obras foram criadas happenings, body art, performance, instalação, site specific, etc - e para cada uma delas há um conceito específico que a caracteriza como linguagem. Pensemos nas distinções feitas por Renato Cohen, onde os happenings são um desenvolvimento da body art, mas se desprendem do corpo como suporte e se concentram na obra como um acontecimento circunscrito em um tempo. Ainda segundo o autor, na medida em que estabelecem relação mais estreita com as artes cênicas, os happenings vão dar surgimento às performances, no entanto, enquanto os happenings têm como característica fundamental a temporalidade, a performance se caracteriza pela relação do tempo com o espaço (COHEN, 2007).

Contudo, é preciso considerar que os artistas não se adéquam a estas formatações, e trabalham nos interstícios destas categorizações, provocando com frequência situações de indistinção ou de impossibilidade de classificação das linguagens. Mais do que isso, a situação criada pelo indiscernimento faz com que essa diferenciação seja irrelevante.

Se, como vimos, o vocabulário controlado assegura uma uniformização dos dados que são inseridos e recuperados em uma base, se as categorias se tornam muito específicas e irreprodutíveis em outros contextos, o controle vocabular pode perder sua característica de uniformização e se tonar cada vez mais específico dentro da poética de cada artista, fragilizando, portanto sua função inicial.

O que acabamos de observar a partir destes impasses demonstrados entre a documentação museológica e arte contemporânea, deu-se em função de uma mudança de paradigma da arte, que alterou a concepção de objeto artístico, desestruturando a lógica linear que organizava as linguagens, os estilos e as técnicas.

Esta desestruturação é lida por Belting (2006) a partir do tema do fim da história da arte, que, segundo ele, não significa o fim da história da arte, mas apenas o esgotamento de uma tradição específica de arte, moderna e européia. Há então o surgimento de diversas histórias da arte possíveis, tantas quantas linguagens artísticas. Com ausência de um discurso de tendências totalizantes, ocorre uma proliferação de discursos específicos, que pretendem abordar universos muito particulares. A teoria da arte se torna cada vez mais compartimentada e específica e as teorias dos artistas substituem a idéia de uma teoria da arte única.

Houve não apenas uma mudança no discurso, na lógica de produção e legitimação da arte, mas também uma mudança do que pode ser considerado arte. Os antigos critérios, fundamentados em analises da imagem, da técnica e da temática, não se aplicam às novas linguagens que estão sendo produzidas. É o que Belting exemplifica através da metáfora da peça de teatro:

[...] os intérpretes de arte pararam de escrever a história da arte no velho sentido, e os artistas desistiram de fazer uma história da arte semelhante. Soa assim o sinal de pausa para a velha peça, quando não há muito tempo está sendo executada uma nova peça, que é acompanhada pelo público segundo o velho programa e conseqüentemente é mal compreendida (BELTING, 2006, p. 24).

Outro ponto fundamental da análise de Belting (2006) é o entendimento da obra de arte como algo que oscila entre idéia e objeto. Segundo o autor, a morte da teoria clássica da arte se dá quando a obra se transforma em teoria e se distancia do suporte material, que a apartava do mundo. Se uma obra de arte era reconhecida por suas propriedades técnicas e estéticas, agora o que diferencia um objeto de arte dos outros objetos cotidianos é uma questão conceitual.

Se a obra de arte se define, não mais por suas propriedades materiais, mas pelo ato filosófico de sua concepção, há um ponto fundamental que pos- 
sibilita a aproximação da teoria sobre o fim da arte (ou da história da arte) de Belting dos incorporais de Anne Cauquelin.

O conceito de obras incorporais, cunhado por Cauquelin (2008), propõe que determinadas linguagens da arte contemporânea podem não mais ser definidas por suas propriedades materiais, mas por seu significado simbólico.

A autora constrói seu argumento afirmando que o processo de comunicação é composto por um dispositivo material a partir do qual são comunicados os significados, e por elementos abstratos trazidos simbolicamente por quem está recebendo a informação. Através de um exemplo simples e cotidiano, como dizer às crianças "Não vão muito longe!" a autora ressalta que, o que está sendo comunicado às crianças vai além do que as palavras carregam. Não é necessário nem possível dizer exatamente o quão perto ou longe as crianças deveriam ir, porque "Elas [as crianças] não levam em conta as palavras em si, simples indicações em torno das quais se trama a significação" (CAUQUELIN, 2008, p. I0). Há, no processo de comunicação verbal,

[...] um invólucro de sentido que dá suporte às palavras [...] um invólucro que envolve as palavras, mas que não é a soma das palavras, um fundo que envolve os elementos da lembrança sem se confundir com eles: trata-se ali, é claro, dos incorporais familiares (CAUQUELIN, 2008, p. I I).

Do mesmo modo, toda obra de arte constrói uma narrativa, e se coloca como veículo corporal para transmissão de significados incorporais. $O$ que acontece nas obras contemporâneas é a valorização do exprimível em detrimento do veículo corporal que lhe expressaria. Na relação obra - espectador há um universo ilimitável de possibilidades de significados que surgem no momento da abordagem, e que tem a obra de arte apenas como ponto de partida. No caso de uma pintura, por exemplo, a superfície da tela é o suporte material que sustenta os subsídios responsáveis pela comunicação. $O$ artista combina cores e formas (elementos materiais) que vão traduzir uma imagem, uma mensagem, temas e conceitos.Arranjados na superfície da tela de acordo com determinada lógica, esses elementos são como a frase dita às crianças no exemplo de Cauquelin, serão a parte concreta da comunicação, que revestida de um "invólucro de sentido" (CAUQUELIN, 2008, p. I I) possibilita a transmissão da informação.

Nas obras de arte incorporais, identificadas como arte contemporânea, ocorre uma problematização desse suporte que será revestido de significados. Há uma alteração do que será considerado obra de arte, o foco se transfere do suporte material, para este invólucro de significados.

Vale ressaltar ainda o conceito de estética relacional. Esse termo é trabaIhado por Bourriaud (2009a) para caracterizar a poética de artistas do final do século $X X$ e da primeira década do século $X X I$. $O$ autor constrói seu argumento a partir da poética de diversos artistas entre estas a obra de Tiravanija referida anteriormente. Segundo Bourriaud (2009a), a estética relacional é marcada por um enfrentamento à sociedade do espetáculo, à padronização de comportamentos e sua relação com o consumo. Constitui-se ainda como crítica ao sistema de divisão do trabalho que gera sociedades de classe e aos mecanismos de atribuição de valores através do capital, entre diversos outros aspectos da pós-modernidade.

No caso específico da estética relacional, o que se vislumbra não é mais extrapolar os limites impostos pela arte (ou pela história da arte), tampouco os limites físicos do objeto artístico. Aqui, a obra de arte se desenvolve independentemente da materialidade, tendo as relações humanas como ponto de partida e como objetivo. Segundo Bourriaud (2009a, p. 43, grifo nosso):

A questão não é mais ampliar os limites da arte, e sim testar sua capacidade de resistência dentro do campo social global.Assim, a partir 
de um mesmo conjunto de práticas vemos surgir duas problemáticas totalmente diversas: ontem, a insistência sobre as relações internas do mundo artístico, numa cultura modernista que privilegiava o novo e convidava à subversão pela linguagem; hoje a ênfase sobre as relações externas numa cultura eclética, na qual a obra de arte resiste ao rolo compressor da 'sociedade do espetáculo'.

Aqui há uma inversão do que poderíamos chamar obra de arte. Tradicionalmente, ela estava relacionada ao espaço e à materialidade; a delimitação física de um objeto fazia a separação da arte e da realidade. Para a estética relacional, essa relação é substituída, e a delimitação da obra de arte passa a ser uma duração momentânea. $O$ que se considera obra não é mais o espaço físico a ser percorrido (mesmo que em alguns casos apenas com os olhos), mas se torna um tempo a ser vivenciado. Para o autor “[...] Já não se pode considerar a obra contemporânea como um espaço a ser percorrido [...]. Agora ela se apresenta como uma duração a ser experimentada, como uma abertura para a discussão ilimitada" (BOURRIAUD, 2009a, p. 20-2I).

Esse postulado inverte os preceitos da arte moderna. A sacralização do objeto artístico, tão discutido na era da reprodutibilidade técnica (BENJAMIN, 1987), na estética relacional, é transformada. Já não há mais objeto a ser sacralizado, mas há, em contraposição, a sacralização de um momento, de um tempo ocorrido da obra de arte.

Esse tipo de linguagem, frequente na arte contemporânea, depende do trabalho da documentação para existir, ainda que somente enquanto memória ou informação de uma obra definitivamente acabada.

Sobre esta questão, Lima (2003) discute a ausência do objeto material no processo artístico.A autora coloca que a efemeridade das linguagens faz com que a informação museológica se constitua a partir de registros. Nas palavras da autora:

Tais proposições estão baseadas em conteúdos que alcançam a primazia do conceito, em detrimento das outras questões tratadas pelos gêneros artísticos tradicionais, calcados no objeto de arte e sua fatura. A inexistência dessas obras depois das apresentações é a tônica do processo. Em fases posteriores às apresentações dessas propostas artísticas, a partir dessa noção de fazer arte, elas só estarão aptas para discussões e estudos dos pesquisadores caso sejam documentadas e gerem registros (texto, imagem, som) (LIMA, 2003, p. I34).

De acordo com o argumento de Lima (2003), é possível concluirmos portanto, que para que os documentos gerados a partir dos registros possam ser disponibilizados aos pesquisadores, é fundamental que seja possível uma recuperação da informação por meio do sistema de documentação museológica. No entanto, quando a arte contemporânea desloca a lógica de produção e compreensão da obra de arte e se desvincula da materialidade, ela produz um impacto na documentação museológica, que está estruturada sobre uma lógica moderna, hierárquica e linear. precisamente esta diferença entre a lógica moderna da documentação - que trabaIha a noção de documento e de obra de arte a partir da materialidade do suporte - e a nova concepção de obra trazida pela arte contemporânea, que provoca uma desarticulação estrutural que pode dificultar o acesso à informação. Com relação às obras tradicionais, cujo processo de comunicação se dá através da contemplação visual, o sistema de documentação e recuperação da informação é funcional e está adequado a esta tipologia de acervo. No caso das obras de arte contemporânea, há demandas por novas estratégias de documentação museológica que viabilizem a permanência destas linguagens independente de sua materialidade. 


\section{Referências}

BELTING, Hans. O fim da história da arte: uma revisão dez anos depois. São Paulo: Cosac Naify, 2006.

BENJAMIN,Walter.A obra de arte na época de sua reprodutibilidade técnica. In: Obras escolhidas. São Paulo: Brasiliense, 1987.

BOURRIAUD, Nicolas. Estética relacional. São Paulo: Martins Fontes, 2009a.

BOURRIAUD, Nicolas. Pós-produção: como a arte reprograma o mundo contemporâneo. São Paulo: Martins Fontes, 2009b.

CAUQUELIN, Anne. Arte contemporânea: uma introdução. São Paulo: Martins Fontes, 2005.

CAUQUELIN, Anne. Freqüentar os incorporais: contribuição a uma teoria da arte contemporânea. São Paulo: Martins Fontes, 2008.

COHEN, Renato. Performance como linguagem. São Paulo: Perspectiva, 2007.

COSTA, L. C. (Org.). Dispositivos de registros na arte contemporânea. Rio de Janeiro: Contracapa, 2009.

FERREZ, Helena Dodd. Documentação museológica: teoria para uma boa prática: estudos de museologia. Rio de Janeiro: Ministério da Cultura, Instituto do Patrimônio Histórico e Artístico Nacional, 1994. p.65-74. (Cadernos de ensaios, 2). FREIRE, Cristina. Poéticas do processo: arte conceitual no museu. São Paulo: Iluminuras, 1999.

LE GOFF, Jacques. Documento / monumento. In: . História e memória. 5. ed. Campinas: UNICAMP, 2003a.

LE GOFF, Jacques. Memória. In: . História e memória. 5. ed. Campinas: UNICAMP, 2003b.

LIMA, Diana F. C. Ciência da Informação, Museologia e fertilização interdisciplinar: informação em arte, um novo campo do saber. 2003. Tese (Doutorado em Ciência da Informação)-IBICT, UFRJ, Rio de Janeiro, 2003.

LOUREIRO, M. L. N. M.A documentação museológica entre a arte e a ciência. In: GRANATO, M.; SANTOS, C. P.; LOUREIRO, M. L. N. M. (Org.). Museu de Astronomia e Ciências Afins - MAST. Rio de Janeiro: MAST, 2008. (MAST colloquia, I0) MOMA.The collection. Disponível em: <http://www.moma.org/collection/browse_results.php?criteria=0\%3AAD\%3AE\%3A7479\&page_number=2\&template id $=$ I \&sort_order $=\mid>$.Acesso em: 07 set. 2013.

POMIAN, K. Coleção. In: ENCICLOPÉDIA Enaudi: memória história. Lisboa: Imprensa Nacional, Casa da Moeda, 1984. v. I. p. 5I-86.

SMIT,J.W.A documentação e suas diversas abordagens. In: GRANATO, M.; SANTOS, C. P.; LOUREIRO, M. L. N. M. (Org.). Museu de Astronomia e Ciências Afins - MAST. Rio de Janeiro: MAST, 2008. (MAST colloquia, I0) 